\title{
Implementasi Algoritma Harmony Search Untuk Penjadwalan Produksi Plastik
}

\author{
Hendry Setiawan ${ }^{* 1}$, Oesman Hendra Kelana ${ }^{2}$, Dennys Gunawan ${ }^{3}$ \\ 1,2,3 Universitas Ma Chung \\ hendry.setiawan@machung.ac.id ${ }^{\star}$
}

\begin{abstract}
Abstrak
Permasalahan yang sering terjadi pada perusahaan yang bekerja di bidang produksi kantong plastik adalah masih tingginya kerusakan hasil produksi (afal). Hal ini dikarenakan operator yang bertugas untuk menjadwalkan produksi masih kurang memiliki kemampuan dan pengalaman yang mencukupi untuk menjadwalkan produksi, sehingga menyebabkan kemungkinan terjadinya kesalahan penjadwalan yang tinggi. Untuk memecahkan permasalahan tersebut, penelitian ini bertujuan untuk menciptakan sebuah aplikasi yang dapat merekomendasikan jadwal produksi. Algoritma yang digunakan untuk membuat aplikasi ini menggunakan algoritma harmony search. Solusi penjadwalan produksi akan direpresentasikan dalam bentuk nada-nada. Setiap nada akan improvisasi terus menerus hingga mencapai nada terbaik yang mampu memberikan rekomendasi jadwal yang terbaik. Proses pengujian yang dilakukan terhadap aplikasi dengan menggunakan data sebanyak 28 order memberikan hasil bahwa aplikasi ini dapat melakukan penjadwalan dengan tingkat keakuratan mencapai $98 \%$.
\end{abstract}

Kata kunci: Harmony search, Produksi, Penjadwalan

\begin{abstract}
The Problem that is often faced in company working on manufacturing of plastic bags is still high rate of defective products. This problem happens because defective products always exist in every production process, which is known in technical language as afal. This is because the operator which is assigned on production scheduling doesn't have sufficient ability and experience on production scheduling which results in the high probability of unappropriated scheduling. To solve that problem, this research aims to create an application which is able to recommend a production schedule. The algorithm used to create this application is harmony search algorithms. This production scheduling solution will be represented in the form of tones. Each tone will be improved continuously until it reaches the best tone that can give the best schedule recommendation. The application testing process which used 28 data order gives result that this application can do scheduling process with 98\% accuration rate.
\end{abstract}

Keywords: Harmony search, Production, Scheduling

\section{Pendahuluan}

Penjadwalan menjadi salah satu permasalahan yang sering dihadapi oleh setiap perusahaan. Dengan dilakukannya penjadwalan yang baik membawa pengaruh pada setiap perusahaan dalam peningkatan kinerja mesin sehingga biaya produksi akan berkurang dan waktu produksi menjadi lebih cepat [1]. Penjadwalan secara garis besar dapat dibedakan dalam penjadwalan untuk job shop dan flow shop. Permasalahan yang membedakan antara job shop dan flow shop adalah pola aliran kerja yang tidak memiliki tahapan-tahapan proses yang sama. Untuk dapat melakukan penjadwalan dengan baik maka waktu proses kerja setiap mesin serta jenis pekerjaannya perlu diketahui, waktu yang dimaksud dapat diperoleh melalui pengukuran waktu kerja, jenis serta jumlah pekerjaan diperoleh dengan melakukan pengamatan dari operator pada bagian tertentu. Setelah diketahui jenis serta waktu proses kerja setiap mesin yang akan dijadwalkan maka proses penjadwalan dapat dilakukan [2].

Secara umum kendala penjadwalan yang sering terjadi pada sebuah perusahaan adalah ketidakmampuan operator dalam membagi job pada mesin, sehingga kerusakan hasil produksi semakin membengkak. Hal ini sering dijumpai pada perusahaan yang proses 
produksinya berdasarkan permintaan, dimana setiap konsumen memiliki pesanannya dengan kriteria yang berbagai macam dengan jumlah pesanan yang besar. Salah membagi job pada mesin akan memberikan dampak pada job yang lainnya, dan kemungkinan berdampak seberapa besar kerusakan hasil produksi yang akan ditanggung perusahaan, karena pada akhirnya akan memberikan kerugian bagi perusahaan.

Permasalahan yang sering terjadi di lapangan adalah masih tingginya kerusakan hasil produksi perusahaan. Sebab, dalam setiap proses produksi pasti menghasilkan kerusakan hasil produksi atau dalam bahasa teknisnya adalah afal. Afal ini akan didaur ulang sehingga dapat diproduksi kembali namun kualitas dari bijih plastik afal lebih rendah harga jualnya dibandingkan dengan sebelumnya. Berdasarkan hasil wawancara dengan pemilik perusahaan, operator yang bertugas untuk menjadwalkan produksi dirasa kurang memiliki kemampuan dan pengalaman untuk menjadwalkan produksi. Ketidakmampuan operator dalam menjadwalkan produksi akan memberikan afal yang semakin tinggi. Sehingga apabila afal semakin tinggi maka akan merugikan perusahaan.

Untuk memindahkan beban kerja dari orang kepada sebuah mesin maka diperlukan algoritma optimasi. Optimasi digunakan untuk pencarian fungsi nilai maksimum atau minimum dari sebuah permasalahan linier, dinamis, non linier ataupun yang lainnya sehingga dapat menghasilkan nilai lokal optimum maupun global optimum [3]. Optimasi ini juga menunjuk pada proses pencarian elemen terbaik dari sekumpulan pilihan yang tersedia seperti yang telah dilakukan pada permasalahan pemetaan empat warna dengan harmony search [4]. Penelitian yang lain dilakukan dengan harmony search untuk mendapatkan kombinasi daya masingmasing unit pembangkit, serta mendapatkan fungsi biaya termurah dengan tidak melanggar ketentuan yang ada, yaitu equality dan inequality/optimal power flow (OPF) [5].

Berdasarkan pada penelitian yang melibatkan optimasi didalamnya, maka untuk membantu memecahkan permasalahan kerusakan hasil produksi perusahaan, dibuatlah sebuah aplikasi pengoptimalan penjadwalan produksi dengan algoritma harmony search. Algoritma harmony search merupakan salah satu pendekatan metaheuristik yang terinspirasi oleh musisi Jazz yang terus-menerus memperbaiki harmoni hingga menemukan harmoni terbaik yang diinginkan. Dengan adanya aplikasi ini, diharapkan mampu memberikan jadwal produksi yang optimal.

\section{Metode Penelitian}

\subsection{Analisis Kebutuhan dan Pengumpulan data}

Permasalahan penjadwalan produksi ini menjadi sorotan peneliti karena termasuk salah satu sebab perusahaan mengalami kerugian. Hal ini disebabkan karena adanya kesalahan jadwal produksi. Kesalahan jadwal produksi akan sangat mempengaruhi jumlah kerusakan hasil produksi (afal). Berdasarkan hasil pengamatan peneliti, diketahui bahwa selalu terdapat afal dalam setiap proses mengerjakan order. Untuk sekali pengerjaan order, afal dapat mencapai sekitar $\pm 6 \%$ - 10\% dari kapasitas mesin yang dikerjakan.

Afal selalu terjadi di awal proses pengerjaan order. Hal ini dikarenakan untuk mendapatkan hasil yang memuaskan dibutuhkan keadaan produksi yang stabil. Hasil produksi yang masih belum stabil inilah yang akan menjadi afal. Faktor lain yang menyebabkan tingginya afal adalah ukuran kapasitas mesin. Semakin besar ukuran kapasitas mesin, afal yang didapat juga semakin besar. Faktor lainnya adalah semakin banyak order, afal yang diterima akan semakin kecil. Afal dapat berupa kantong plastik, bongkahan plastik, plastik yang rusak, dsb. Terdapat sebanyak 17 mesin yang digunakan pada penelitian ini dimana mesin tersebut memproduksi kantong plastik jenis PP seperti yang tertera pada Tabel 1.

Pembuatan jadwal yang sesuai dengan diharapkan dilakukan dengan pemodelan jadwal dalam bentuk slot-slot, yang setiap slot merepresentasikan sebesar $100 \mathrm{~kg}$. Pemodelan ini juga dilakukan pada setiap kapasitas mesin ke dalam bentuk slot-slot. Selanjutnya setiap slot pada kapasitas mesin akan memiliki nomor urut yang berfungsi untuk mengetahui batasan ukuran mesin. Berikut adalah tabel permodelan dalam bentuk slot untuk mesin kategori kecil double, mesin kecil, mesin sedang, dan mesin besar yang dapat dilihat pada Tabel 2, Tabel 3, Tabel 4, dan Tabel 5.

Uji coba data penelitian ini dilakukan pada data purchase order (PO) dan tersimpan di database yang dimiliki oleh sebuah perusahaan. Data yang diambil adalah data dari tanggal 2 Maret 2015 - 11 April 2015 dengan jumlah pesanan sebanyak 17 pesanan. Beberapa aspek yang perlu diperhatikan adalah ukuran produk dan jumlah pesanan.

KINETIK Vol. 2, No. 2, Mei 2017: 71-82 
Tabel 1. Daftar Mesin Jenis PP

\begin{tabular}{|c|c|c|c|c|c|}
\hline \multirow{2}{*}{$\begin{array}{l}\text { No. } \\
\text { Mesin }\end{array}$} & & & \multicolumn{2}{|c|}{ Ukuran } & \multirow{2}{*}{$\begin{array}{l}\text { Kapasitas } \\
(\mathrm{kg}) / \text { hari }\end{array}$} \\
\hline & & & minimal & maksimal & \\
\hline 1 & $\begin{array}{l}P \\
P\end{array}$ & $S$ & $20 \times 10$ & $40 \times 18$ & 700 \\
\hline 2 & $\begin{array}{l}P \\
P\end{array}$ & $S$ & $20 \times 10$ & $40 \times 18$ & 700 \\
\hline 3 & $\begin{array}{l}P \\
P\end{array}$ & $S$ & $20 \times 10$ & $40 \times 18$ & 700 \\
\hline 4 & $\begin{array}{l}P \\
P\end{array}$ & K & $20 \times 8$ & $40 \times 22$ & 400 \\
\hline 5 & $\begin{array}{l}P \\
P\end{array}$ & K & $30 \times 7$ & $40 \times 22$ & 400 \\
\hline 6 & $\begin{array}{l}P \\
P\end{array}$ & $S$ & $20,25 \times 15$ & $50 \times 35$ & 700 \\
\hline 7 & $\begin{array}{l}P \\
P\end{array}$ & K & $20 \times 6$ & $40 \times 23$ & 400 \\
\hline 8 & $\begin{array}{l}P \\
P\end{array}$ & K & $20 \times 6$ & $40 \times 23$ & 400 \\
\hline 9 & $\begin{array}{l}P \\
P\end{array}$ & $\mathrm{~K}$ & $20 \times 6$ & $40 \times 23$ & 400 \\
\hline 10 & $\begin{array}{l}P \\
P\end{array}$ & $S$ & $20,25 \times 15$ & $50 \times 39$ & 700 \\
\hline 11 & $\begin{array}{l}P \\
P\end{array}$ & $\mathrm{~K}$ & $20 \times 6$ & $40 \times 23$ & 400 \\
\hline 12 & $\begin{array}{l}P \\
P\end{array}$ & $B$ & $30 \times 30$ & $60 \times 55$ & 1200 \\
\hline 13 & $\begin{array}{l}P \\
P\end{array}$ & $\mathrm{~S}$ & $20 \times 15$ & $40 \times 40$ & 700 \\
\hline 14 & $\begin{array}{l}P \\
P\end{array}$ & $S$ & $20 \times 15$ & $60 \times 36$ & 700 \\
\hline 15 & $\begin{array}{l}P \\
P\end{array}$ & $S$ & $20 \times 15$ & $40 \times 40$ & 700 \\
\hline 16 & $\begin{array}{l}P \\
P\end{array}$ & B & $20 \times 30$ & $80 \times 65$ & 1200 \\
\hline 17 & $\begin{array}{l}P \\
P\end{array}$ & $S$ & $20 \times 10$ & $40 \times 18$ & 700 \\
\hline
\end{tabular}

Tabel 2. Pemodelan Slot pada Mesin Kecil Double

\begin{tabular}{cccc}
\hline \multicolumn{4}{c}{ Mesin Kecil Double } \\
\hline Mesin 1 & Mesin 2 & Mesin 3 & Mesin 4 \\
\hline 0 & 7 & 14 & 21 \\
\hline 1 & 8 & 15 & 22 \\
\hline 2 & 9 & 16 & 23 \\
\hline 3 & 10 & 17 & 24 \\
\hline 4 & 11 & 18 & 25 \\
\hline 5 & 12 & 19 & 26 \\
\hline 6 & 13 & 20 & 27 \\
\hline
\end{tabular}

Tabel 3. Pemodelan Slot pada Mesin Kecil

\begin{tabular}{cccccc}
\hline \multicolumn{7}{c}{ Mesin Kecil } \\
\hline Mesin 5 & Mesin 6 & Mesin 7 & Mesin 8 & Mesin 9 & Mesin 10 \\
\hline 28 & 32 & 36 & 40 & 44 & 48 \\
\hline 29 & 33 & 37 & 41 & 45 & 49 \\
\hline 30 & 34 & 38 & 42 & 46 & 50 \\
\hline 31 & 35 & 39 & 43 & 47 & 51 \\
\hline
\end{tabular}


abel 4. Pemodelan Slot Pada Mesin Sedang

\begin{tabular}{ccccc}
\hline \multicolumn{5}{c}{ Mesin Sedang } \\
\hline Mesin 11 & Mesin 12 & Mesin 13 & Mesin 14 & Mesin 15 \\
\hline 52 & 59 & 66 & 73 & 80 \\
\hline 53 & 60 & 67 & 74 & 81 \\
\hline 54 & 61 & 68 & 75 & 82 \\
\hline 55 & 62 & 69 & 76 & 83 \\
\hline 56 & 63 & 70 & 77 & 84 \\
\hline 57 & 64 & 71 & 78 & 85 \\
\hline 58 & 65 & 72 & 79 & 86 \\
\hline
\end{tabular}

Tabel 5. Pemodelan Slot Pada Mesin Besar

\begin{tabular}{cc}
\hline \multicolumn{2}{c}{ Mesin Besar } \\
\hline Mesin 16 & Mesin 17 \\
\hline 87 & 99 \\
\hline 88 & 100 \\
\hline 89 & 101 \\
\hline 90 & 102 \\
\hline 91 & 103 \\
\hline 92 & 104 \\
\hline 93 & 105 \\
\hline 94 & 106 \\
\hline 95 & 107 \\
\hline 96 & 108 \\
\hline 97 & 109 \\
\hline 98 & 110
\end{tabular}

\subsection{Rancangan dan Implementasi}

Flowchart secara umum untuk algoritma harmony search terdapat pada Gambar 1. Algoritma HS menggunakan pencarian secara random dan menyelesaikannya tanpa informasi secara gradient, sehingga algoritma ini memiliki keuntungan, yaitu fleksibel dan mudah untuk diimplementasikan [6]. Pada algoritma harmony search terdiri dari harmony memory (HM) sebesar harmony memory size (HMS), yang akan menyimpan kandidat vektor solusi [7]. Tahap pertama yang dilakukan adalah menginisialisasikan ukuran HMS, nilai Pitch Adjustment Rate $(P A R)$, nilai Harmony Memory Considering Rate (HMCR) dan batasan maksimum iterasi yang diinginkan [8]. Tahap kedua adalah membangun harmony memory. Harmony memory berisikan harmony sebanyak ukuran HMS yang telah didefinisikan sebelumnya. Tahap ketiga adalah membangkitkan sebuah harmony baru yang diperoleh dengan melakukan pencarian terhadap beberapa nilai yang ada pada harmony memory. Pencarian tersebut didasarkan pertimbangan perbandingan dengan nilai HMCR dan PAR. Tahap keempat adalah pengecekan antara nilai aestetic harmony baru dengan nilai aestetic dari harmony memory yang terendah. Jika nilai aestetic di harmony memory lebih rendah dari nilai aestetic harmony baru, maka harmony dengan nilai terendah akan digantikan dengan harmony baru. Sebaliknya, jika nilai harmony baru lebih rendah dari keseluruhan nilai pada harmony memory, maka tidak ada pergantian harmony. Perbaikan nilai fungsi objektif pada algoritma HS menerapkan improvisasi yang terus ditingkatkan dari iterasi ke iterasi sama seperti perbaikan kualitas suara estetika yang diperbaiki dengan latihan demi latihan [9]. Proses dari tahap ketiga hingga keempat akan diulang hingga mencapai iterasi yang telah ditentukan.

Pembentukan harmony memory pada penelitian ini disesuaikan dengan analisa desain luaran penjadwalan, dimana hasil luaran dari order adalah berupa slot untuk masing-masing mesin yang dikerjakan dalam jangka waktu satu hari kerja. Proses pembentukan slot dikriteriakan menjadi tiga bagian, yaitu:

1. Ukuran kecil, untuk pembagian slot di ukuran kecil terdapat dua pembagian kriteria yaitu mesin kecil double dan mesin kecil biasa. Jika ukuran pesanan termasuk kategori kecil double maka pesanan akan dibagi ke dalam random slot antara slot 0 hingga slot 27 . Jika ukuran pesanan termasuk dalam kategori kecil biasa, maka pesanan akan dibagi ke dalam random slot antara slot 28 hingga slot 51 .

2. Ukuran sedang, jika ukuran pesanan termasuk dalam kategori sedang maka pesanan akan dibagi ke dalam random slot antara slot 52 hingga slot 86 . 
3. Ukuran besar, jika ukuran pesanan termasuk dalam kategori besar maka pesanan akan dibagi ke dalam random slot antara slot 87 hingga slot 110.

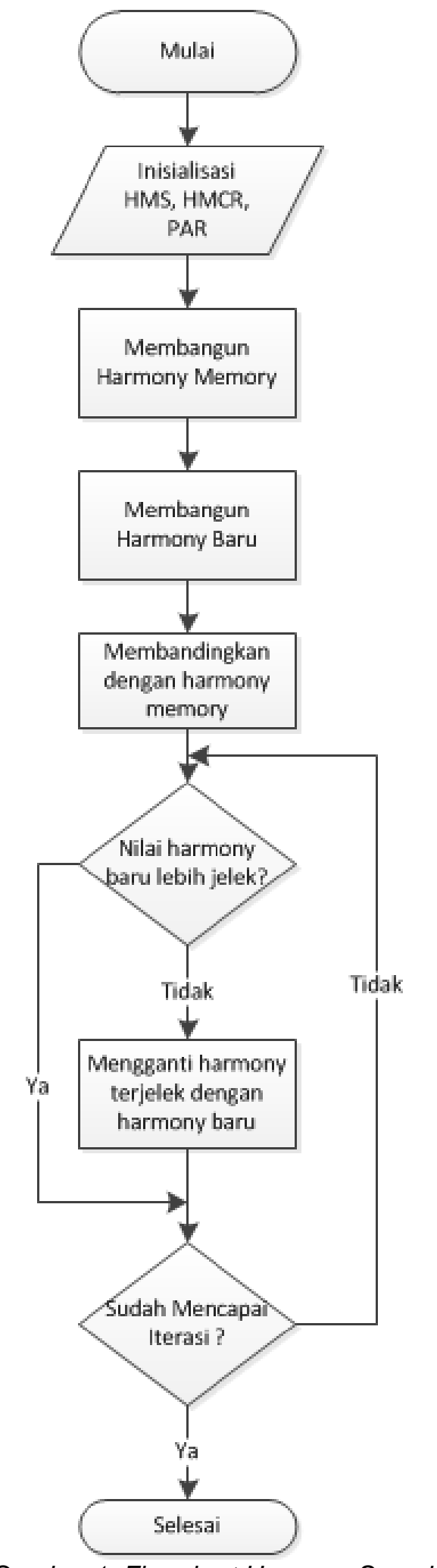

Gambar 1. Flowchart Harmony Search

Flowchart proses membentuk harmony memory dapat dilihat pada Gambar 2. 


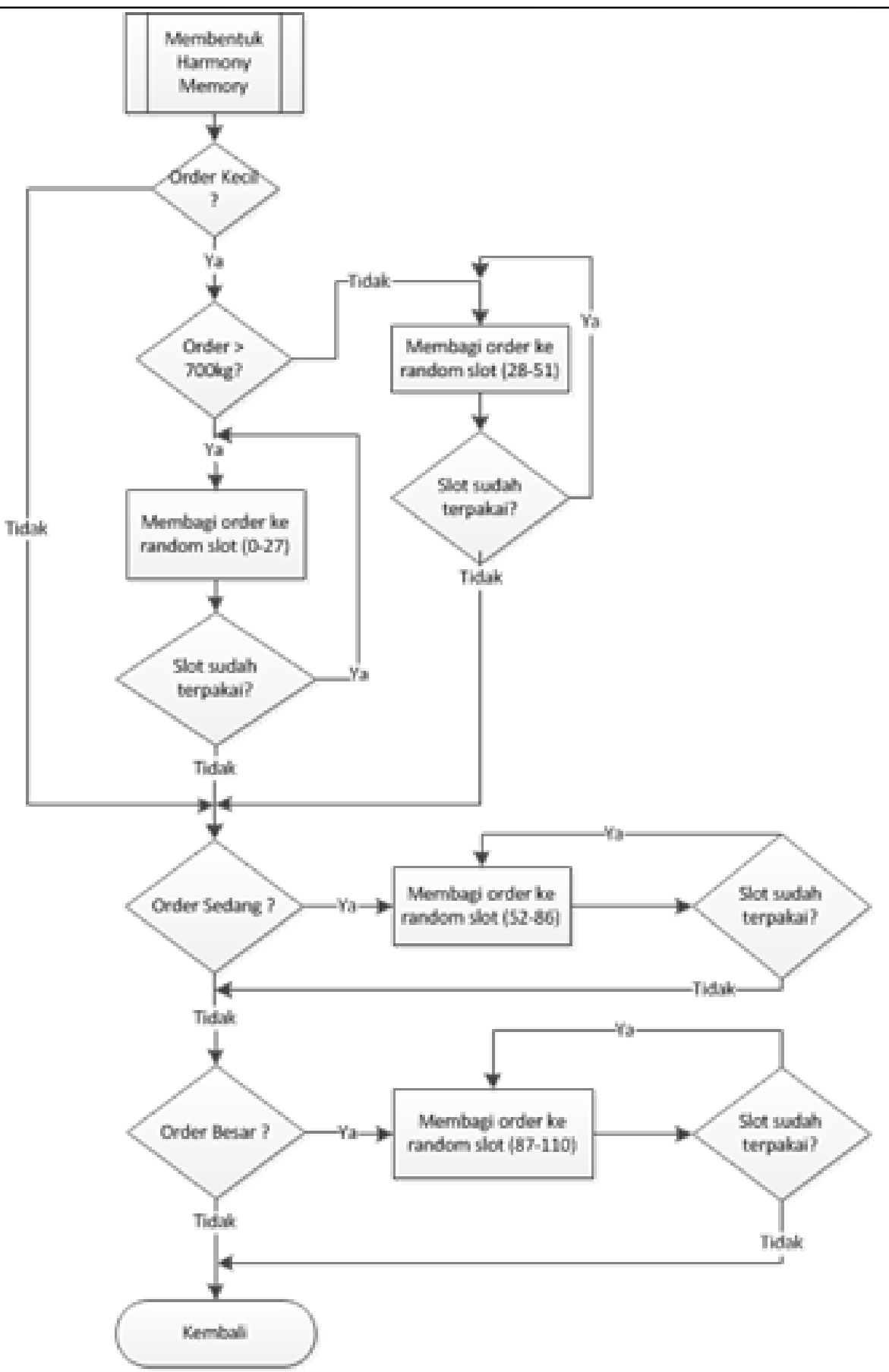

Gambar 2. Flowchart Proses Membentuk Harmony Memory

Proses random tidak mengizinkan nomor slot muncul dua kali dalam satu harmony atau dapat dikatakan bahwa dalam satu harmony tidak boleh terdapat nomor slot yang kembar. Nomor-nomor slot ini juga berisi nomor urut pesanan. Sebagai contoh dapat dilihat pada Gambar 3.

\begin{tabular}{|llllllll|}
\hline harmony & 23,1 & 33,2 & 51,1 & 57,1 & 34,4 & 2,1 & 100,3 \\
\hline
\end{tabular}

Langkah berikutnya dengan Persamaan 1 dan Persamaan 2 menetapkan suatu fungsi evaluasi/aesthetic yang akan digunakan untuk mengevaluasi apakah hasil penjadwalan telah sesuai dengan yang diharapkan [10].

KINETIK Vol. 2, No. 2, Mei 2017: 71-82 


$$
\text { Fungsi Aesthetic }=\sum X_{i}
$$

$$
X_{i}=B_{j k}+\sum B_{j k-1}
$$

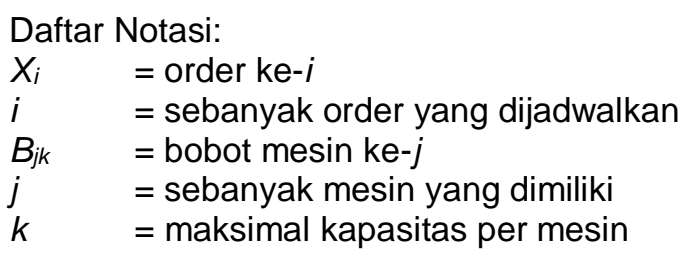

Agar menghitung nilai aesthetic-dari suatu harmony, maka diberikan bobot untuk setiap mesinnya. Bobot akan diberikan berdasarkan setiap kapasitas mesin sehingga untuk setiap ukuran mesin memiliki bobot yang berbeda-beda. Untuk nilai bobot masing-masing mesin dapat dibagi sebagai berikut:

1. Mesin kecil jumbo $(700 \mathrm{~kg})$ dimulai dari $7,6,5,4,3,2,1$.

2. Mesin kecil $(400 \mathrm{~kg})$ dimulai dari 4, 3, 2, 1 .

3. Mesin sedang $(700 \mathrm{~kg})$ dimulai dari $7,6,5,4,3,2,1$.

4. Mesin besar $(1200 \mathrm{~kg})$ dimulai dari $12,11,10,9,8,7,6,5,4,3,2,1$.

Tahapan awal membangkitkan harmony baru dalam harmony search, nada-nada yang berada dalam harmony akan ditingkatkan hingga mendapatkan nada-nada yang lebih tepat. Tahap awal untuk meningkatkan nada adalah membangkitkan sebuah nilai acak antara 0 hingga 1. Jika nilai acak yang muncul lebih kecil dari nilai harmony memory considering rate (HMCR) maka pada nada yang akan ditingkatkan diambil satu nomor slot secara acak dari harmony memory.

Selanjutnya adalah membangkitkan ulang sebuah nilai acak kembali dengan rentang nilai 0 hingga 1 . Jika nilai acak yang muncul lebih kecil dari nilai pitch adjusting rate (PAR) maka nomor slot yang telah terpilih akan ditingkatkan sejumlah bandwidth. Dalam kasus kali ini, bandwidth yang telah ditentukan adalah nilai acak antara $-2,-1,0,+1,+2$. Apabila setelah ditingkatkan sebanyak bandwidth namun nomor slot melebihi batas ukuran. Proses penambahan nilai lama dengan bandwdith akan diulang kembali. Selain itu, nomor slot tidak diizinkan terjadi kesamaan antar nada dalam satu harmony. Jika terjadi kesamaan maka nilai setelah ditambah dengan bandwidth akan di tambahkan dengan nilai acak antara $-1,0,+1$. Jika setelah ditambahkan terdapat nomor slot yang melewati batas ukuran maka akan ditambahkan dengan nilai acak antara -2 atau +2 . Pengecekan untuk melebihi batas ukuran atau terdapat nomor yang sama dalam satu harmony akan terus diulang hingga memenuhi syarat.

Sebaliknya jika nilai acak antara 0 hingga 1 melebihi dari nilai PAR, maka nomor slot yang terpilih akan digunakan tanpa ada peningkatan sebesar bandwidth. Namun, untuk pengecekan tetap dilakukan agar tidak terjadi kesamaan nomor dalam satu harmony atau nomor slot yang melebihi batas. Pengecekan akan menggunakan penambahan nilai antara -1 , 0,1 yang diambil secara acak. Sama seperti proses sebelumnya, jika nomor melewati batas maka akan ditambahkan dengan nilai acak antara -2 atau +2 . Pengecekan akan terus diulang hingga memenuhi syarat.

Begitu pula pada tahap awal, jika nilai acak antara 0 hingga 1 memiliki nilai yang lebih besar dari HMCR maka sistem akan membangkitkan sebuah nomor slot baru yang diacak. Batasan slot untuk mengacak nomor slot yang baru ditentukan berdasarkan ukuran order. Pada proses membangkitkan nada baru juga harus melewati pengecekan. Pengecekan yang dilakukan adalah agar tidak terdapat nomor slot yang sama dalam satu harmony.

Proses diatas akan dilakukan untuk seluruh nada yang dimiliki dalam harmony memory. Jika seluruh nada untuk harmony yang baru telah terbentuk maka fungsi aesthetic akan menghitung nilai harmony. Proses berikutnya adalah membandingkan nilai aesthetic antar harmony dalam harmony memory. Setelah didapatkan nilai aesthetic terendah di harmony memory maka akan dibandingkan dengan nilai aesthetic pada harmony baru. Jika nilai aesthetic pada harmony yang baru lebih baik dari nilai aesthetc terjelek di harmony memory 
maka harmony yang memiliki nilai aesthetic terjelek akan digantikan dengan harmony baru. Seluruh proses diatas akan dilakukan sebanyak iterasi yang telah ditentukan.

\subsection{Pengujian Aplikasi}

Pengujian dilakukan dalam beberapa tahap, yaitu uji kesamaan proses yang terkait pembentukan dalam harmony search, akurasi, dan kecepatan.

\section{Hasil Penelitian dan Pembahasan}

\subsection{Hasil Uji Kesamaan Proses}

Uji kesamaan proses berguna untuk melihat kemiripan antara rancangan desain sistem dengan hasil setelah diimplementasikan. Proses-proses yang diuji, yaitu sebagai berikut.

1. Proses Pengolahan Data Pesanan

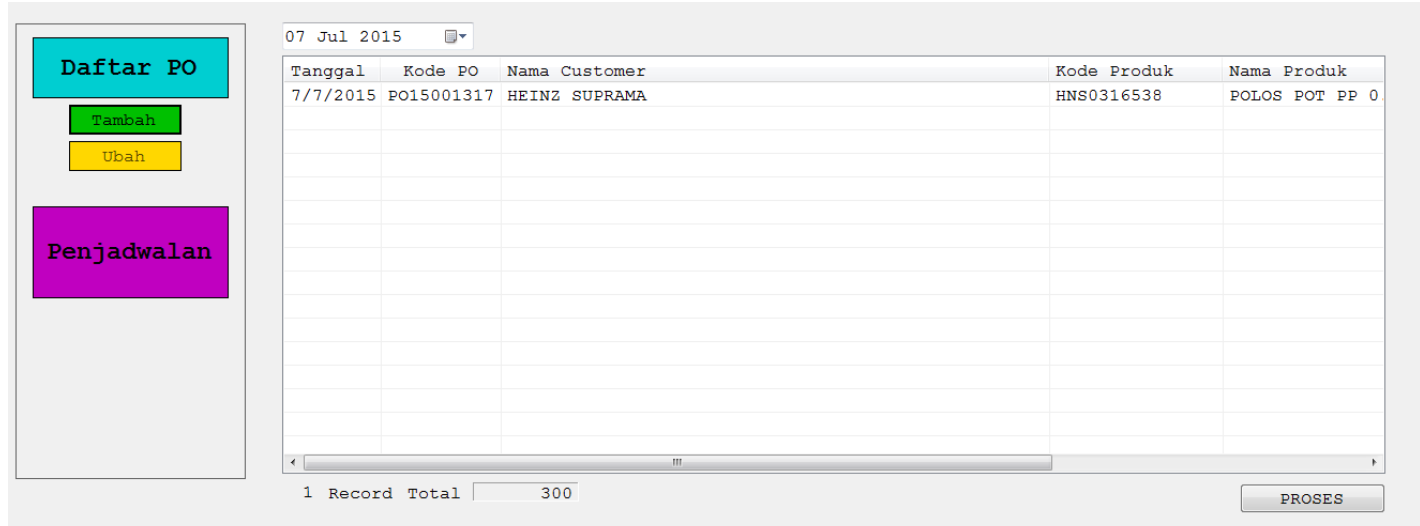

Gambar 4. Pengolahan Data Pesanan

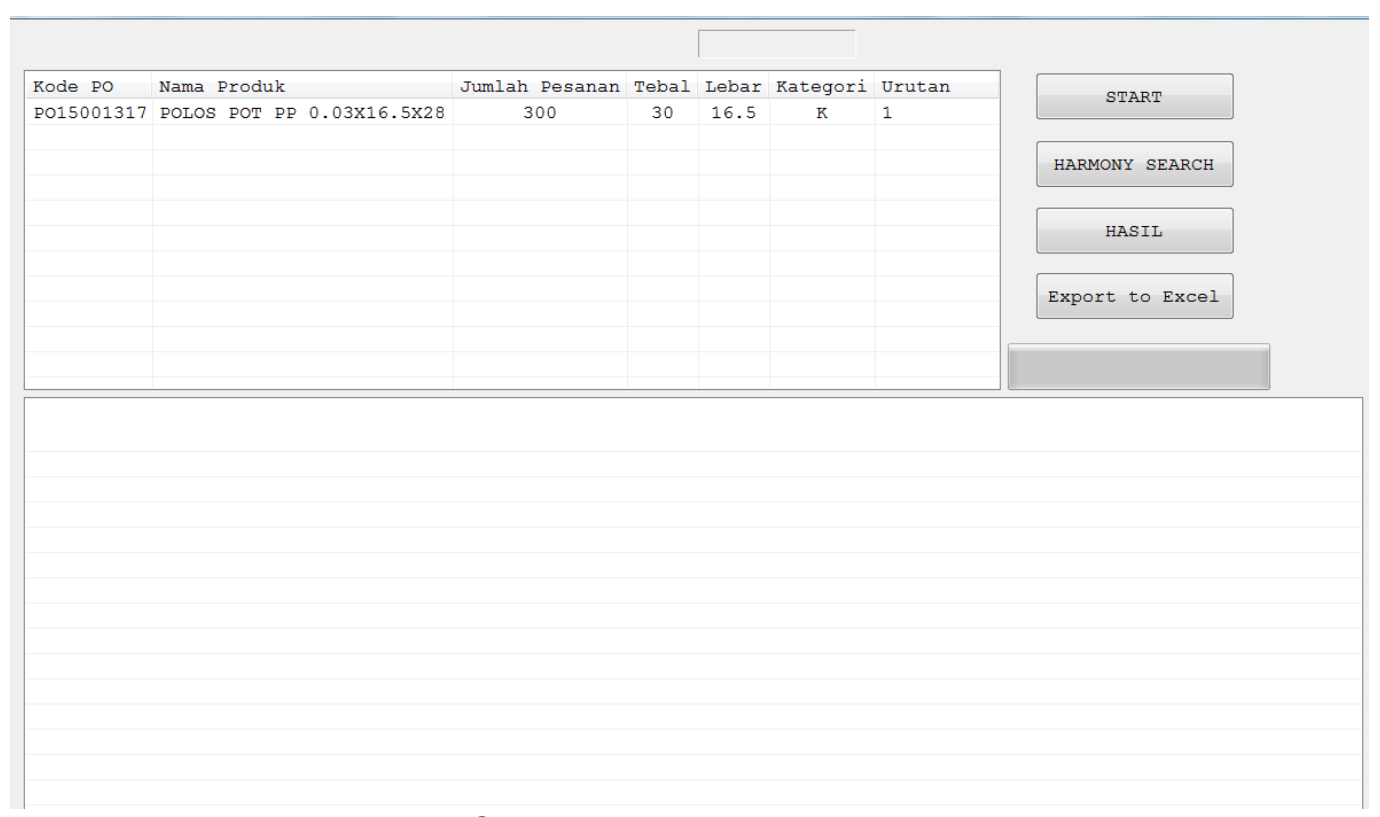

Gambar 5. Form Penjadwalan

Pada Gambar 4 berupa form yang digunakan untuk menambahkan dan mengedit data yang didapatkan perusahaan pada waktu purchase order. Gambar 5 merupakan bentuk form yang akan melakukan pemilihan purchase order yang akan dijadwalkan dengan menggunakan algoritma harmony search.

Pada Gambar 6 terdapat sejumlah purchase order yang telah dipilih beserta detail di dalamnya serta pembentukan awal sebuah harmony memory. Pada Gambar 7 melakukan pengecekan terhadap pembentukan harmony memory baru. 


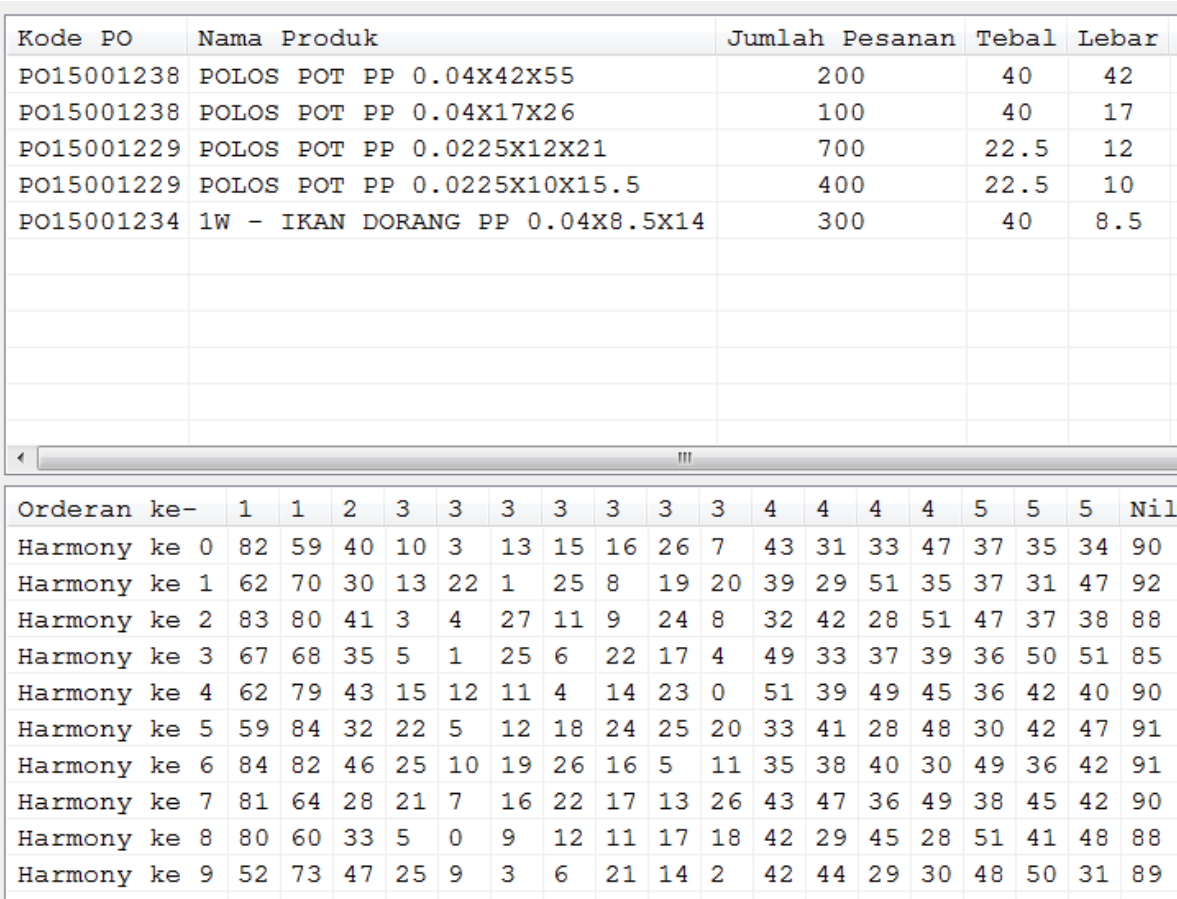

\section{Gambar 6. Harmony Memory}

\begin{tabular}{|c|c|c|c|c|c|c|c|c|c|c|c|c|c|c|c|c|c|c|}
\hline Orderan ke- & 1 & 1 & 2 & 3 & 3 & 3 & 3 & 3 & 3 & 3 & 4 & 4 & 4 & 4 & 5 & 5 & 5 & Nil. \\
\hline Harmony ke 0 & 65 & 70 & 36 & 0 & 27 & 6 & 19 & 7 & 12 & 18 & 43 & 35 & 44 & 40 & 38 & 51 & 29 & 91 \\
\hline Harmony ke 1 & 85 & 77 & 46 & 9 & 4 & 5 & 21 & 1 & 6 & 10 & 30 & 36 & 40 & 37 & 35 & 50 & 47 & 87 \\
\hline Harmony ke 2 & 52 & 73 & 44 & 19 & 26 & 25 & 18 & 10 & 22 & 11 & 47 & 35 & 42 & 33 & 51 & 29 & 36 & 89 \\
\hline Harmony ke 3 & 59 & 80 & 32 & 5 & 18 & 2 & 6 & 8 & 15 & 27 & 30 & 41 & 31 & 28 & 36 & 29 & 37 & 87 \\
\hline Harmony ke 4 & 60 & 69 & 48 & 27 & 17 & 6 & 24 & 16 & 18 & 11 & 31 & 40 & 36 & 51 & 45 & 47 & 37 & 90 \\
\hline Harmony ke 5 & 53 & 72 & 44 & 17 & 2 & 10 & 16 & 9 & 19 & 21 & 39 & 35 & 32 & 49 & 43 & 30 & 51 & 90 \\
\hline Harmony ke 6 & 59 & 71 & 38 & 6 & 17 & 18 & 3 & 23 & 20 & 4 & 47 & 31 & 33 & 50 & 28 & 39 & 44 & 89 \\
\hline Harmony ke 7 & 74 & 66 & 38 & 10 & 8 & 14 & 2 & 3 & 27 & 26 & 42 & 44 & 48 & 29 & 28 & 36 & 51 & 92 \\
\hline Harmony ke 8 & 86 & 71 & 50 & 16 & 15 & 26 & 8 & 12 & 11 & 4 & 38 & 39 & 34 & 40 & 48 & 49 & 31 & 89 \\
\hline Harmony ke 9 & 69 & 75 & 28 & 24 & D & 8 & 21 & 3 & 17 & 2 & 37 & 31 & 43 & 44 & 38 & 49 & 45 & 91 \\
\hline harmony baru & 57 & 72 & 46 & 10 & 2 & 12 & 21 & 3 & 26 & 4 & 39 & 44 & 33 & 45 & 28 & 29 & 50 & 88 \\
\hline nilai lam & $\mathrm{x}$ & 5 & 1 & 7 & 5 & 5 & 9 & 1 & 7 & 8 & 5 & $\mathrm{x}$ & 3 & 9 & 6 & 3 & 5 & \\
\hline berubah k. & $>$. & $>$. & $>$. & $>$. & $>$. & $<$. & $\cdot$ & $<$. & $<$. & $>$. & $>$. & $>$. & $<$. & $>$. & $>$. & $>$. & $<$. & \\
\hline
\end{tabular}

\section{Gambar 7. Harmony Memory Baru}

\subsection{Hasil Uji Coba Akurasi}

Untuk memastikan hasil implementasi berjalan dengan baik, perlu dilakukan pengujian keakuratan. Dengan adanya pengujian, dapat diketahui kelebihan dan kekurangan aplikasi ini sehingga dapat dilakukan perbaikan untuk kedepannya. Seluruh pengujian akan dilakukan dengan HMS 10 harmony, nilai PAR 0.3, nilai HMCR 0.9 dan iterasi sebanyak 12000. Pengujian ini menggunakan data sebuah perusahaan dari tanggal 2 Maret 2015 hingga 11 April 2015.

Pada Tabel 6 adalah pengujian ini dilakukan sebanyak order yang ada di antara tanggal 2 Maret 2015 hingga 11 April 2015. Salah satu contohnya adalah pesanan pada tanggal 8 April 2015. Terdapat 12 order dengan total keseluruhan order adalah $3000 \mathrm{~kg}$ yang dapat dilihat lebih jelas pada Gambar 7. 
Setelah dijadwalkan dan diproses dengan algoritma harmony search maka seluruh order akan memiliki nomor-nomor slot seperti pada Gambar 8.

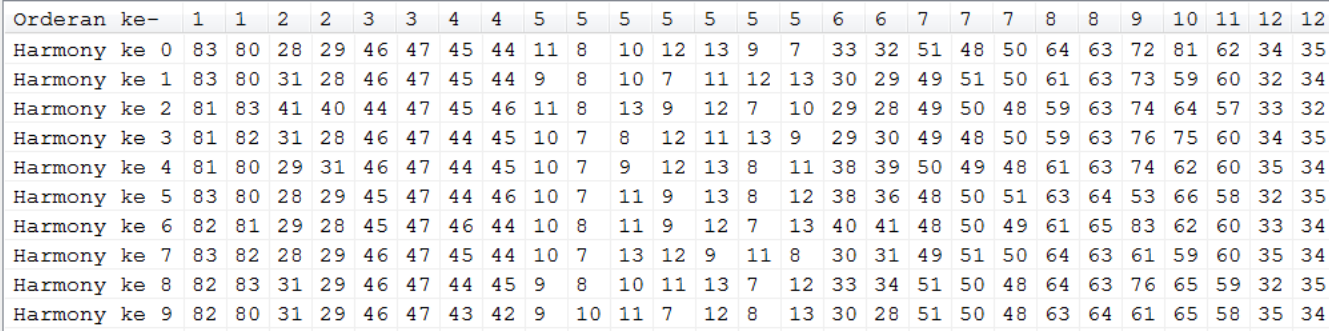

Gambar 8. Nomor Slot yang Dimiliki Tiap Order

Berdasarkan hasil penjadwalan pada Gambar 9, diketahui bahwa terdapat 2 order yang tidak menempati posisi seharusnya, yaitu order nomor 3 dan order nomor 13. Sehingga ketepatan penjadwalan dapat dihitung $100 \%-((2 \times 100 / 4700) \times 100 \%)=95,8 \%$.

\begin{tabular}{|c|c|c|c|c|c|c|c|c|c|c|c|}
\hline \multirow[t]{8}{*}{$\operatorname{esin} 4$} & mesin 5 & mesin 6 & mesin 7 & mesin 8 & mesin 9 & mesin 10 & mesin 11 & $\operatorname{mesin} 12$ & mesin 13 & mesin 14 & mesin 15 \\
\hline & 9 & & 8 & 2 & 3 & 3 & 14 & 15 & 1 & 16 & 6 \\
\hline & 11 & & 10 & 2 & 11 & 4 & 14 & 15 & 1 & 16 & 6 \\
\hline & & & 12 & 7 & 12 & 4 & 14 & 15 & 13 & & 13 \\
\hline & & & 12 & & & 4 & 14 & 15 & & & \\
\hline & & & & & & & 14 & 15 & & & \\
\hline & & & & & & & & 15 & & & \\
\hline & & & & & & & & 15 & & & \\
\hline
\end{tabular}

Gambar 9. Hasil Penjadwalan Tanggal 11 April 2015

\subsection{Hasil Uji Coba Kecepatan}

Uji coba kecepatan mengukur lama waktu proses aplikasi untuk menghasilkan sebuah jadwal produksi sebuah perusahaan dengan percobaan order pada tanggal 8 April 2015, yaitu 1 menit 47 detik. Percobaan ini menggunakan 12 order dengan 27 nada, untuk nilai PAR menggunakan 0,3 dan nilai HMCR 0,9. Iterasi yang digunakan sebanyak 12000 iterasi. Sedangkan proses penjadwalan yang biasanya dilakukan berlangsung selama 45 menit.

\section{Kesimpulan}

Berdasarkan penelitian yang telah dilakukan, kesimpulan yang dapat diambil adalah:

1. Rekomendasi jadwal produksi dengan menggunakan algoritma harmony search telah berhasil dilakukan.

2. Tingkat keakuratan aplikasi mencapai $98 \%$ dengan nilai PAR 0.3, HMCR 0.9, HMS 10 dan diiterasi sebanyak 12000 kali.

3. Dalam segi uji coba kecepatan, aplikasi dapat dikatakan lebih memuaskan dari pada penjadwalan secara manual. Sebab, untuk menjadwalkan secara manual diperlukan waktu 45 menit. Sedangkan dengan menggunakan aplikasi ini hanya memerlukan waktu 1 menit 45 detik.

\section{Referensi}

[1] M. Astuti, "Studi Penjadwalan Job Shop Untuk Meminimalkan Waktu Keseluruhan Menggunakan Pendekatan Algoritma Artificial Immune," Jurnal Angkasa, Vol. 5, No. 1, Pp. 19-28, 2013.

[2] N. Masruroh, "Analisa Penjadwalan Produksi Dengan Menggunakan Metode Ampbell Dudeck Smith, Palmer, Dan Dannenbring Di Pt," Loka Refraktoris Surabaya. Penelitian UPN “Veteran," Vol. 3, No. 2, Pp. 158-171, 2006.

[3] S. Patil And D. Patel, "An Overview: Improved Harmony Search Algorithm And Its Applications In Mechanical Engineering," International Journal Engineering Science and Innovative Technology., Vol. 2, No. 1, 2013.

[4] B. Daham And M. Mohammed, "Parameter Controlled Harmony Search Algorithm For Solving The Four-Color Mapping Problem," International Journal of Computer and Information Technology, Pp. 3-6, 2014. 
[5] E. A. Zuliari, "Harmony Search Algorithm (HSA) Untuk Optimal Power Flow (OPF)," Jurnal Iptek, Vol. 17, No. 1, Pp. 23-34, 2013.

[6] M. Huang, S. Guo, X. Liang, And X. Jiao, "Application Of Improved Harmony Search Algorithm In Test Case Selection," Journal of Software, Vol. 9, No. 5, Pp. 1170-1177, 2014.

[7] C. Worasucheep, "A Harmony Search With Adaptive Pitch Adjustment For Continuous Optimization," Reviews Harmony Search, Vol. 4, No. 4, 2011.

[8] Z. Geem, K. Lee, And Y. Park, "Application Of Harmony Search To Vehicle Routing," American Journal of Applied, Vol. 2, No. 12, Pp. 1552-1557, 2005.

[9] I. Aulia, E. Nababan, And M. Muchtar, "Penerapan Harmony Search Algorithm Dalam Permasalahan Penjadwalan Flow Shop," Dunia Teknologi Informasi-Jurnal, Vol. 1, No. 1, Pp. 1-7, 2012.

[10] R. Putra, "Penerapan Algoritma Harmony Search Pada Resource Constrained Project Scheduling Problem (RCPSP)," SKRIPSI Jurusan Matematika-Fakultas MIPA UM, 2013. 